\title{
THE PHILOSOPHICAL AND BELIEF FOUNDATIONS OF THE SOCIAL SCIENCES AND CONTEMPORARY RUSSIAN SOCIETY
}

\author{
Marat P. Buzskiy \\ Volgograd State University, Volgograd, Russian Federation
}

\begin{abstract}
The main focus of this article is to study the correspondence between modern Russian society and the social sciences. Drawing attention to the fact that the process of theoretical modeling of modern society is consistently lagging behind the rate of change, the author proposes, as a methodological and philosophical foundations of social science, the category of "social forms", which provides a kind of synthesis of Russian social and cultural identities where its ethnic content is combined with the concepts of social philosophy and sociology, providing the appearance of real subject for social science - existence of contemporary Russia.

Identifying the disadvantages of the Soviet social science, as well as looking at contemporary approaches to society in Western sociology, the author notes their abstractness, because of which national and other features of this particular society are omitted. The hypothesis put forward by the author is that the basis and the condition of the synthesis or correlation of social and ethnic in the modern Russian society presents itself the integrity of the social form being the basis of social activities and communication processes and converting redundancy of internal and external environment in an ordered manifold, the main criterion of which is the compliance of the existing and arising reality with the basic cultural code of ethnic or national-cultural identity of the society. In conclusion the author provides recommendations for the philosophical and methodological "adjustment" of the modern social sciences in Russia.
\end{abstract}

Key words: conceptual model, identity, social form, integrity, relevance, objectivity, communication, intersubjectivity.

УДК 02.41

ББК 87.6

\section{ФИЛОСОФСКО-МИРОВОЗЗРЕНЧЕСКИЕ ОСНОВЫ ВЗАИМОДЕЙСТВИЯ ОБЩЕСТВЕННЫХ НАУК И СОВРЕМЕННОГО РОССИЙСКОГО СОЦИУМА}

\author{
Марат Павлович Бузский \\ Волгоградский государственный университет, г. Волгоград, Российская Федерация
}

\begin{abstract}
Аннотация. Статья посвящена исследованию проблемы соответствия между современным российским обществом и общественными науками. Обращая внимание на то, что процесс теоретического моделирования современного общества постоянно отстает от темпов его изменений, автор предлагает в качестве методологической и мировоззренческой основы обществознания категорию «социальной формы», которая обеспечивает своеобразный синтез российской социокультурной самобытности - ее этнонациональное содержание совмещается здесь с понятиями социальной философии и социологии, обеспечивая появление для общественных наук их реального предмета - существования современной России.

Выявляя недостатки советского обществознания, а также рассматривая современные подходы к обществу в западной социологии, автор отмечает их абстрактность, в силу которой упускаются национальные и другие особенности данного конкретного общества. Гипотеза, выдвигаемая автором, состоит в том, что основанием и условием синтеза, или корреляции социального и этнонационального в современном российском обществе, является целостность социальной формы, которая лежит в основе общественной деятельности и коммуникаций и перерабатывает избыточность внутренней и внешней среды в упорядоченное многообразие, главный критерий достижения которого - соответствие существующей и рождающейся реальности с базовым культурным этническим кодом, или с национально-культурной самобытностью данного обще-
\end{abstract}


ства. В конце статьи приводятся рекомендации по философско-методологической «корректировке» современных общественных наук в России.

Ключевые слова: концептуальная модель, самобытность, социальная форма, целостность, соответствие, предметность, коммуникация, интерсубъективность.

Одной из характерных тенденций современности является опережение темпов изменения общественной системы по отношению к ее познанию и освоению: система меняется быстро и мало предсказуемо, а концептуальная модель общества, в которой бы выделялся его устойчивый «каркас», отсутствует. Когда мы говорим о таких моделях, конечно, имеются в виду не общепринятые понятия - рыночное общество, информационная среда, глобализация и др., а именно такая их связь, в которой бы в теоретическом аспекте раскрывался интегральный образ российского общества.

Это предполагает опору на принцип объективности, понимание обществом самого себя «изнутри», четкое различение возможного и невозможного, соотношение субъективного и объективного и др. Огромное значение имеют более или менее ясное представление о будущем и способность «распознать» это будущее в структурах и динамике настоящего. Получается, что сам социальный «факт» для общественных наук - особенно для социальной философии и социологии - должен рассматриваться в связи с моделью целостности общества, которая сегодня еще не сложилась. А то, что исследуется - общественное мнение, изменение социальных структур, мотивации людей, манипуляции общественным сознанием, медиатексты и др., - это феномены, статус которых (их бытийные характеристики в составе целого) не поставлен в общую системную связь друг с другом и оказывается взаимно не «проявленным».

Что означает такая модель? Конечно, она предполагает определенные рамки абстракции: при всех общих проявлениях информационного общества или рыночной системы важным ограничением становится учет феномена российской самобытности и уникальности бытия страны: Россия находится в мире, но сохраняет свой способ «присутствия» в нем. Именно этот способ присутствия создает ту общую социальную форму, в рамках которой открывается российская общественная и гражданская идентичность страны для самой себя. Моделирование страны в научных исследованиях именно через выявление такой формы позволяет увидеть и конкретные предметы исследования - социальные «факты», и явления как таковые.

В современных координатах информационного пространства и времени общественная среда как целое постоянно ускользает от ее теоретического моделирования и концептуализации именно в связи с игнорированием (скорее, незнанием особенностей) этой социальной формы. И, как следствие, в современном обществе постоянно воспроизводится некий «слой» неопределенности, который часто является источником конфликтов и напряженности. А возникшая еще в XX в. особая функция - конструирование мира иллюзий и мифотворчества, направленная на создание упрощенного образа реальности через СМИ, рекламу и массовую культуру, по-своему подтверждает постоянное запаздывание процесса распредмечивания объективных общественных процессов и изменений: они не имеют специфического для России «экрана рассмотрения».

Конечно, сегодня проводятся социологические исследования, создаются программы и аналитические статьи, монографии и т. д. Однако все эти исследования, как правило, не направлены на выяснение собственного методологического обоснования российской социальной онтологии и поэтому так или иначе воспроизводят социальную реальность лишь частично. В этой связи можно утверждать, что в нашем обществоведении еще нет ясности в следующем вопросе: какие требуются условия для формирования его собственного предмета, способного перевести реальность общественной жизни в форму науки? В каком ракурсе должны рассматриваться факты и явления общественной жизни, чтобы они могли быть фактами научной теории?

Вопрос этот оказывается довольно сложным, поскольку необходимо выявлять тот «срез» общества, в котором сохранялась бы 
живая реальность и вместе с тем была представлена ее объективность, связь с законами самой общественной системы. Если делать упор на объективность, то может «испариться» весь тот пласт субъективности, который отличает одну историческую эпоху от другой, а Россию - от всего остального мира. Так произошло в нашем отечественном обществоведении в недавнем прошлом. В странах социализма, которые на основе философии и идеологии марксизма сделали упор именно на эти законы, возникла рациональная модель общества, в которой предметом рассмотрения оказалось изменение динамики и структуры общества на самом общем уровне. Общественные науки, изучая диалектику общественных изменений, проводя постоянный мониторинг текущего состояния общества, выявляли его ведущие тенденции, а также возникающие перекосы и диспропорции.

В однозначное соответствие друг с другом были поставлены идеологическая модель общества, его научное рассмотрение и сама общественная жизнь. Их отрыв друг от друга не допускался, а потому личная свобода, частная жизнь граждан, любые другие феномены, которые в это единство не укладывались, выпадали из научного рассмотрения или трактовались как некоторые «отклонения». И хотя именно на основе такого жесткого научно-идеологического рационализма СССР выдержал огромные трудности предвоенных лет, войны и послевоенного восстановления, прямой перевод самой общественной системы в ее научно-диалектическое исследование оказался слишком ограниченным образом самого общества и личности. Возникшие в послевоенный период культурные «оттепели» и особенно культура 60-х гг., в значительной степени расширившая собственное пространство и ценность личности, показали, что общественным наукам (в первую очередь - философии и идеологии) необходимо ориентироваться на более сложную связь с обществом, допуская здесь методологический плюрализм.

Но наша страна, которая с этим не справилась теоретически, пропустила стихийное развертывание несоциалистической сферы и связанное с этим ослабление воздействия социалистической идеологии на население. И несмотря на то что философия стала осва- ивать новые категории в рамках исторического материализма - «духовное производство», «личность и общество», «социальные пространство и время» и др., в целом перестроить философско-научное освоение общества с учетом мира личности, особенностей социального и т. д. в тот период не получилось. В результате (с учетом и многих других факторов) СССР перестал существовать.

Таким образом, начиная с 90-х гг. наше общество оказалось без необходимого для него теоретического «прикрытия». В результате сегодня остро ощущается дефицит эффективной научной теории - как незаменимого средства извлечения из общества объективных рациональных процессов и структур, которые в процессе их системного моделирования не только позволяют прийти к самосознанию и самоопределению общества, обоснованию его стратегий, целей и идеалов, но и позволяют уточнить и скорректировать основания и принципы деятельности современных социальных институтов, осуществлять социально-культурную экологию содержания существующих коммуникаций, восстановить воздействие «первичного» общественного бытия и связанного с ним бытия природы, которые девальвируются на основе разрастания искусственной среды, формируемой СМИ, избыточностью текстовых миров, процессов бесконечных интерпретаций, постепенно все более теряющих отношение к оригиналу и сохранение его статуса как первоисточника. Наша современность показывает, что нерешенность вопроса о статусе и философскометодологическом базисе общественных наук так же пагубна для социума и личности, как и недавний исторически противоположный процесс - рационально-научное конструирование общества.

В современной западной социологии и философии проблема нахождения соответствия между обществом и его научной моделью оказывается весьма актуальной. Идет постоянное уточнение категории «социальное», пересматривается ее содержание, исследуются направления общественных изменений, взаимодействие субъекта и объекта, социального времени и пространства. В методологическом аспекте идет исследование особенностей «социальных фактов» и их обоб- 
щение, особенностей социокультурного, ценностного, информационного и других направлений детерминации, которые действуют в жизни общества.

В целом в современных парадигмах неклассического и постнеклассического анализа общества в разных направлениях философии и социологии происходит своеобразная «замена» социальной и личностной субъективности различными текстовыми и знаковыми конструкциями: широкое и вариативное поле межсубъектных взаимодействий, выступавшее всегда источником рождения и «объективации», материализации форм (средств) общения и действий, теперь уже сформировано как набор схем мышления и поведения, что в значительной мере ослабляет и сам статус субъекта в обществе, включение его характеристик в научные модели общества.

Прежде всего в центре внимания оказывается информационный детерминизм - воздействие информации на содержание и структуру современного общества. Так, М. Кастельс отмечает, что современное индустриальное пространство «организовано вокруг новых потоков информации, которые сводят вместе и, вместе с тем, разделяют одновременно... свои территориальные компоненты. И по мере того, как логика информационнотехнологического устройства просачивается от производителей информационно-технологического устройства к его пользователям во всей области производства, новая пространственная логика расширяет охват, создавая множественность глобальных сетей, пересечения которых трансформируют само понятие промышленности, означающее теперь не место положение фабрик, но пространственные потоки» [11, с. 369-370]. Если информация действует объективно как некоторая универсальная причинная основа (а этот ее статус связан с тем, что информация - единственная реальность, которая «обгоняет» в своем росте саму общественную систему и тем самым оказывается ее универсальным «организатором»), то меняется и содержание пространства социального взаимодействия людей.

Оно оказывается в значительной мере «объективированным» и овеществленным, причем не только на основе активного фор- мирования новой текстовой среды, но и стандартами (технологиями и правилами) заданности коммуникаций, что резко ограничивает проявление субъективности в общении людей и обесценивает само существование их внутреннего мира. Социальные коммуникации происходят в контексте некоторой виртуальности, которую, как «незавершенное бытие», сами социальные взаимодействия превращают в особую «видимость». Поэтому вполне закономерно, что «распространение Интернета способствует социальной изоляции, разрыву общественных связей и разрушению семейной жизни, когда анонимные индивидуумы практикуют беспорядочную коммуникабельность, отказываясь от личного взаимодействия» [2, с. 66].

Информатизация общества выступает как источник упрощения или даже отрицания самого бытия социального. В современной социологии любые концепции предполагают «слабую» социальность, которая не является самодостаточной реальностью и объективно сама себя не воспроизводит и не сохраняет. Это выступает как результат «десубъективизации» социума - отказ от его трактовки как формы, пространства, результата и условия коллективной деятельности социальных субъектов. Социум становится проводником коммуникаций, но не содержанием бесконечно разнообразного исторически изменяющегося мира человека.

Так, с точки зрения Э. Гидденса, «социентальные общности существуют только в контексте интерсоциальных систем, рассредоточенных вдоль пространственно-временных пределов... общества, которые представляют собой социальные системы, “выделяющиеся" на фоне ряда других системных отношений, в которые они включены. Их особое положение обусловлено четко выраженными структуральными принципами, используемыми в процессе всеобъемлющей “кластеризации институтов" во времени и пространстве» [8, c. 241-242].

Живая межсубъектная связь здесь замещена или объективирована некоторыми формальными алгоритмами, стереотипами, в которых размещены и сняты субъектные позиции людей. Гидденс видит в содержании социума не формирующуюся субъективность 
(смыслы, символы, установки и др.), но опятьтаки организующие формы коммуникаций. Он пишет: «Структура как регулярно организованные наборы правил и ресурсов выходит за пределы времени и пространства. Она поддерживается, проявляется и координируется через “отпечатки” в памяти и характеризуется “отсутствием субъекта". Социальные системы, в которых структура постоянно присутствует и реализуется, наоборот, охватывают действия людей, расположенные и воспроизводимые во времени и пространстве... Центральной в теории структурации является теорема о дуальности структуры... В соответствии с понятием дуальности структуры, структурные качества социальной системы являются как средством, так и результатом практик, которые они регулярно организуют» $[9$, c. $60-61]$.

Нечто сходное мы находим и в концепции общества П. Бурдье. Здесь выражением социальности выступает габитус - «система прочных приобретенных предрасположенностей, структурированных структур, предназначенных для функционирования в качестве структурирующих структур, то есть в качестве принципов, которые порождают и организуют практики и представления, которые объективно приспособлены для достижения определенных результатов, но не предполагают сознательной нацеленности (субъектов. $M$. Б.) на эти результаты и не требуют особого мастерства. Объективно "регулируемые" и "регулярные", они могут исполняться коллективно, не будучи продуктом организующего действия режиссера» [7, с. 17-18].

Таким образом, если в классической социологии общество как система включает в себя субъективность (в виде деятельности, значений и смыслов, ценностей, установок и др.), которая имеет статус активной движущей силы общества, но не объективируется (в силу принципиальной несовместимости или различий субъективного и объективного), то в современных концепциях социума информационно-текстовая среда переводит эту субъективность в свои безличные формы, и тем самым субъекты коммуникации становятся внутренне «пустыми»: они существуют как проводники сообщений и коммуникаций - те, кто передают сообщения и кто их воспринимает. Они «привязаны» к коммуникациям как их неотъемлемое звено.

Если рассмотреть этих «субъектов» самих по себе, то они оказываются «молчаливым большинством» или «массой». Так, в модели общества Ж. Бодрийяра социальные агенты лишены своей субъективности, составляя некое стихийное сообщество людей. Мас$\mathrm{ca}$, в понимании Бодрийяра, состоит из тех, кому «предназначено быть уже только многоликим результатом функционирования тех самых моделей, которым не удается их интегрировать и которые, в конце концов, предъявляют их только в качестве статистических остатков» $[4$, с. 10$]$. Эти «остатки»индивиды, которые взяты «сами по себе», то есть вне организующей их текстово-коммуникативной среды. Но они не пассивны, а являются стихийной, непредсказуемой силой: ведь искать здесь смысл или рациональные мотивации нельзя. В то время как социальное прекращает свое существование, масса симулирует социальное, имитирует общественное взаимодействие. Таким образом, Бодрийяр раскрывает общество, в котором исчезает субъектная сторона. Здесь действуют маргиналы, ориентированные на зрелищность, но не на идейность, смысл и подлинный контакт с Другим. Не интегрированные ни в одну общность или структуру в качестве субъектов, то есть не имея самосознания таких субъектов, они находят выход в псевдосолидарности с такими же опустошенными и невостребованными агентами, легко становясь средством для любых манипуляций.

Итак, важным выводом является тесная связь между «смертью социального» и утратой членами общества своего статуса субъектов. Действительно, смысловое содержание социальной жизни существует только через общение и действия социальных субъектов, обладающих представлением о собственной самости, определяющих и выбирающих как себя, так и свое место в социуме. Именно поэтому само по себе социальное общение (коммуникации), в котором преобладает информация, а не субъекты, которые ее воспринимают, отбирают и осмысливают, является искажением реальности.

Эти концепции показывают модель информационного общества и соответствующие 
социологические описания общества «как такового». Французской, немецкой или американской специфики общества здесь нет. Здесь также нет и возможностей раскрыть особенности современного социума в силу «снятия» в нем субъектной стороны. Однако сложности с моделированием социального возникают и у наших исследователей, которые в определении социальных коммуникаций принимают позицию социальных субъектов, но не связывают их с базовым условием самобытности общества. Так, В.И. Грачев определяет социокультурную коммуникацию как «универсальную синергетическую систему взаимодействия людей в социокультурном пространстве и времени на основе коммуникативно-познавательного процесса создания, обмена, хранения и трансляции культурных ценностей в их духовном выражении и материальном воплощении по различным коммуникационным каналам в виде разнообразных текстов культуры, артефактов, фиксирующих результаты человеческой деятельности, эстетический опыт, смыслы, ценности и идеалы человеческой жизни, а также информационных сообщений о них в современном социокультурном и художественном пространстве» [10, с. 71].

Здесь упущено, что эти коммуникации существуют в рамках специфического для России пространства и времени, что на них воздействуют особенности сознания и образа жизни современной России. Однако и те концепции, в которых раскрываются особенности повседневной среды существования людей, их «жизненный мир», также не выявляют именно данное конкретное общество.

Хороший пример - работа П. Бергера и Т. Лукмана «Социальное конструирование реальности» (1995). Здесь реальность повседневной жизни рассматривается как интерсубъективный мир. Он, как считают авторы, конструируется интерсубъективным сознанием людей в их взаимодействии. В этом процессе важную роль играет структура пространства и времени этой повседневной среды. Другой важный фактор - язык. Он объективен как знаковая реальность и соединяет разные «системы» или миры повседневности.

Эти авторы считают, что «структура социальной реальности конституируется субъективными значениями» [3, с. 33], кото- рые образуются в ходе повседневной жизни и общения индивидов. Образуемая реальность «интерпретируется людьми и имеет для них субъективную значимость в качестве цельного мира. Это мир, создающийся в их мыслях и действиях, который переживается ими в качестве реальности» $[3$, с. 38$]$. Таким образом, функцию субъекта здесь выполняет интерсубъективное поле (пространство) общения, которое выражено смыслом и значениями, а потому не существует как нечто объективное само по себе: оно целиком конституируется сознанием и позицией индивидов в их взаимных коммуникациях. Но характер объективности здесь возникает на основе складывающегося порядка, который возникает и сохраняется до рождения и деятельности каждого индивида - в традициях и действиях предшествующих поколений. «Реальность повседневной жизни оказывается уже объективированной, то есть конституированной порядком объектов, которые были обозначены до моего появления на сцене. Средством формирования социального порядка является язык, используемый в повседневной жизни, он постоянно предъявляет мне необходимые объективации и устанавливает порядок, в рамках которого приобретают смысл и значение и эти объективации, и сама повседневная жизнь» [3, с. 41].

В этой работе четко показано, что общественная жизнь - продукт взаимодействия индивидов, причем именно единство прошлого и настоящего здесь соединяет «порядок» (структуры общества) и его смыслы, а общей системой, в которой все это интегрируется, является язык. Последний, «благодаря своей способности выходить за пределы "Здесь-итеперь", соединяет различные зоны реальности повседневной жизни и интегрирует их в единое смысловое поле. Выходы за пределы (трансценденции) имеют пространственное, временное, социальное измерение» [3, с. 69].

Определенной проблемой этой, бесспорно, важной работы является отсутствие объяснения оснований формирования объективных систем и отношений в обществе: эти системы (экономическая, социальная, культурная и др.), с одной стороны, противостоят индивидам как надличностные объективные реальности, которые открывают направления 
действий для людей; с другой стороны, эти системы изменяются и взаимодействуют на уровнях, которые люди не осознают и не воспринимают непосредственно. Каким же образом они возникают из процесса общения и деятельности индивидов, социальных групп и общностей? Указанные авторы обходят эту проблему. Общей формой или результатом социального конструирования реальности, согласно Бергеру и Лукману, является символический универсум, понимаемый как «матрица всех социально объективированных и субъективно реальных значений; целое историческое общество и целая индивидуальная биография рассматриваются как явления, происходящие в рамках универсума... символический универсум упорядочивает также историю. Он связывает коллективные события в единое целое, включающее настоящее, прошлое и будущее» $[3$, с. 158, 168].

Все эти информационные, феноменологические, социально-коммуникативные, социологические «срезы» общества не раскрывают его общую форму или структуру, в способе организации которой они существуют и проявляются. Данная форма (а ее можно назвать и системой, и субъектом) существует не только как совокупность культурно-предметного мира, созданного в ходе общественно-исторического процесса на основе способа производства, соединения общественной практики и совокупности социальных институтов, языка, символов, ценностей и др., но и как «коллективный организм» - этнонациональное образование, в котором интегрированы биосоциальная, культурная и общественно-воспроизводственная реальности. Особой проблемой является нахождение тех опосредований, которые синхронизируют этническое и социальное несмотря на различия их собственных темпов исторических изменений: социальное как сфера рационально деятельностного преобразования реальности изменяется всегда «быстрее», чем происходят трансформации этносоциального организма, например, переход этнического в национальное.

В словаре по социальной философии этнос определяется как «динамическая система, претерпевающая непрерывный внутренний трансформационный процесс, однако, имеющая и некоторую устойчивость в своей измен- чивости. Культура - это фактор и критерий этнической устойчивости, система внутриэтнических констант. Безусловно, в самой культуре есть внутренняя особенность: она меняется от эпохи к эпохе, от одной социальной группы в составе этноса к другой. Но пока она сохраняет свое качественное своеобразие, этнос существует как автономное целое, даже если он утрачивает единую территорию, язык, единство антропологического типа и т. Д... Качественное своеобразие культуры составляют те наиболее устойчивые образцы деятельности, которые складываются в период становления этнической системы... Они составляют “код” внутриэтнической информации, формируя для этноса его особое отношение к миру, органично увязывая во времени его последующие и предшествующие состояния... Понятие этноса определяет именно меру взаимосвязи единого культурно-хозяйственного типа и общей исторической судьбы» $[13$, с. 541$]$.

Таким образом, социальная форма определяет границы и пространство того кода внутриэтнической информации, который выступает своеобразной общей детерминантой, которая определяет и «распределяет» в социальном пространстве и времени все общественные связи, события и процессы. Данный «код» является особой константой, которая обеспечивает тождество (устойчивость) данного народа самому себе как субъекта, который сохраняется исторически, перерабатывая и изменяя содержание своего хозяйственноэкономического, культурного, социального и политического пространства. Можно сказать, что социум «задан» не только социальными субъектами, но и более глубинным субъектно-информационным отношением регулирования, в котором он и обнаруживает свои субъектно-детерминирующие свойства. Оставаясь тождественным себе исторически, данный код, с другой стороны, не препятствует развитию и историческому усложнению общественной системы.

Поэтому не вызывает сомнений, что социум должен иметь такой «механизм интеграции», благодаря которому обеспечивается возможность выявления смысла любой вещи с позиции целостности общественной формы того субъектного видения и оценки вещей со 
стороны данного сообщества, которое складывается в определенный период времени. Общественная форма - это некоторая мера заданности или «проявленности» вещей, уровень их существования для данного общества, его населения, как основа согласования вещей с интересами, целями, практическими и жизненными потребностями людей. Таким образом, общественная форма соединяет субъективное и объективное на любом данном этапе истории; эта форма создает тот особый внутренний каркас, в соответствии с которым любое предметное, объективное бытие разворачивается для своей встречи с субъективным.

Социум, таким образом, «выносит на поверхность» именно ту меру и то мировосприятие, в которых обеспечивается существование данного общества вместе с его структурой и организациями. Это «вынесение наружу» - одновременно и переход (трансформация) отдельного в целое, и выявление тех закономерностей, которые связаны с целым и его обеспечивают; социум - это особый способ преодолеть информационную избыточность, общую неопределенность, выделяя в последней контуры «бытия-для» и все другое оставляя в тени возможного, а для данного сообщества - небытия этого «остатка». Социум «распределяет» бытие и небытие, настоящее и «снятое» в нем прошлое, он постоянно сохраняет способность начинать действие с данного момента, с установленного исходного пункта» [6, с. 107-108].

Таким образом, механизм «вынесения наружу» и доведения до предметно-функционального уровня всего многообразия жизни данного общества не сводится к формам деятельности и коммуникаций: последние сами коренятся в тех процессах объективации и конкретизации, которые осуществляет социальная форма, перерабатывая постоянную информационно-текстовую, стихийно возникающую избыточность внутренней и внешней среды в упорядоченное многообразие, главный критерий достижения которого - соответствие существующей и рождающейся реальности с базовым культурным этническим кодом или с национально-культурной самобытностью данного общества.

Прежде чем пойти дальше, заметим, что недостатком современных исследований об- щественных явлений и процессов является их пропуск действия указанной общей социальной формы. Поэтому остается нераскрытой и сама внутренняя логика вещей и явлений, которые существуют в современном (российском) обществе. Отсюда - огромная роль разных манипуляций, подмен реального мнимым, инструментальное оперирование «плоским» информационным пространством, которые находят место в сегодняшней жизни общества. «Мозаичность» как способ представления реальности в СМИ, краткосрочные прогнозы, отсутствие четких представлений о будущем, к которому движется российское общество - все это результат пропуска того сложного, объективного процесса конкретизации соединение единого и многого - которое осуществляется общей социальной формой.

Здесь актуальным становится выявление тех направлений и средств, на основе которых осуществляется этот процесс, а также рассмотрение их собственного взаимодействия друг с другом.

Прежде всего нужно подчеркнуть, что глубинным основанием «подведения» многообразного под единство является сохранение самой этой социальной формы как субъекта и константы. Близким к этому является позиция П. Бергера и Т. Лукмана, которые поставили язык в центр символического универсума, связывая с ним феномен интерсубъективности. Язык действительно выражает позицию общего социального субъекта (как этноca), но последний выходит в своем бытии за рамки языка. В нем можно найти такие константы, как национальный характер, пространственно-временную форму бытия данного субъекта, проявление коллективного бессознательного, сакральные образы и принципы, которые уходят в социально-историческую память общества и др.

Если рассматривать континуум пространства-времени, в котором существует этноссубъект (как базовая основа социальной формы), то здесь следует подчеркнуть роль прошлого и его традиций. Прошлое время (котоpoe, в частности, зафиксировано в виде музейных композиций, фольклора, духовно-моральных норм и др.) существует в современности как пространство, в котором различаются направления времени настоящего: ори- 
ентация культуры на будущее и ее существование в настоящем - другое, чем те же процессы и отношения в экономически-хозяйственной деятельности, в управлении, в праве и т. п. Отсюда - необходимость пересмотра уже существующих концепций «социальноисторических факторов», из которых складывается общественная система. Общим основанием многофакторности является действие общей социальной формы (субъекта), в логике воздействия которой самостоятельность факторов определяется формами их собственного времени.

Кроме пространства-времени и субъектной позиции, нахождение соответствия между общим (целым) и многообразным происходит и на информационном уровне. Важную роль в исследовании этносов и их участия в современном объективном «социальном конструировании реальности» играет информационный подход, разработанный С.А. Арутюновым. Данный автор подчеркивает, что «механизм существования этнических общностей всех типов, их пространственная стабильность, их временная преемственность... основываются главным образом на связях, которые могут быть описаны в рамках понятия информации. В отличие от генетической информации, передающейся в генной форме, здесь эти информационные связи в основном существуют в виде различных форм коммуникаций. В самом деле, любые отношения, в которые вступают между собой отдельные люди или их группы - отношения экономические, общественные, политические, - непременно выражаются в форме определенной информации» [1, с. 19-20].

Без включения фактора пространства и времени эта констатация довольно абстрактна. Но благодаря им в многообразии направлений информационного общения можно выделить связи синхронные и диахронные. «Синхронные потоки информации выражают все формы общения между людьми, которые осуществляются в данное время и на данном пространстве - словесные, текстовые, образные и др.» [12, с. 14]. Что касается диахронных вертикальных связей, то это - «вся культурная традиция народа, его творческое наследство, передаваемое из поколения в поколение в устной или письменно-литературной, а также в материально-изобразительной форме. Наличием этих непрерывных диахронных инфосвязей между сменяющими друг друга последовательными поколениями этноса обусловлена его преемственность и стабильность во времени, передача этнической традиции в течение веков» $[1$, с. 21$]$.

Если исходить из целостности социальной формы, которая «выносит» глубинное наружу и порождает - вместе с конкретными отношениями субъектов, их потребностями и др. - определенные комплексы функционально связанных предметов, ролей, символов, культурно значимых образов, регулятивных норм и в целом создает некий социальный порядок, то мы подходим к еще одному сложному вопросу: каким образом «расслаиваются», обособляются друг от друга этническое и социальное? В пространстве-времени социальной формы они сосуществуют и взаимодействуют, но по отношению друг к другу устойчиво разделены. Что их разделяет и вместе с тем связывает в нечто общее?

Очевидно, что социальное и этнонациональное существуют в разных темпах времени. Первое всегда опережает второе, так как основано на рациональной связи целей и средств, опирается на достижения науки, производства, а также потому, что само социальное не имеет внутри себя каких-либо «тормозящих» его развитие факторов. Наоборот, его открытость производственно-экономическому процессу - ведь именно социально-классовая структура сформирована экономическим процессом и его отношениями - постоянно сохраняет соответствие между производственнотехнологической и социально-субъектной сторонами. В этом отношении классы и нации имеют разные исторические основания.

Что же тогда их «синхронизирует»? Именно то, что они входят в единство социальной формы, которую еще можно определить как «этносоциальный организм» (Ю.В. Бромлей). Данный автор отмечает: «Составляя базис всех общественных явлений, в том числе и этнических, социально-экономические факторы значительно подвижнее последних. Именно этой относительной консервативностью, а также относительной самостоятельностью этнических свойств и обусловлена возможность сохранения одно и того же по своим 
этническим параметрам этникоса на протяжении нескольких социально-экономических формаций... Но иное дело - этносоциальный организм. Принадлежность к той или иной формации неизбежно придает ему особый характер. Этот факт, по существу, и лежит в основе обычного для нашей литературы последних лет выделения таких историко-стадиальных типов этносоциальных общностей, как племя, народность, буржуазная и социалистическая нации» [5, c. 63].

Комментируя эту позицию Бромлея, Н.А. Моисеева пишет: «Таким образом, в этносоциальном организме соединяются две формы (типа) организации социума: на основе культурных традиций, с одной стороны, и на основе способа производства, в котором выделяются классы, порожденные последним. Получается, что социокультурное пространство этноса как бы проникает в изменяющееся социальное пространство общественно-экономических формаций, сохраняя здесь свою идентичность» [12, с. 15].

В рамках статьи у нас нет возможности продолжать дальше этот анализ. Однако на основе вышесказанного можно подвести некоторые итоги. Этническая идентичность, представляющая собой самобытность данного общества, постоянно включается в процесс его социокультурного воспроизводства, обеспечивая тем самым в итоге собственную динамику общественно-исторического процесса. Если в СССР процесс индустриализации страна «пробежала» за 10 лет вместо нескольких десятилетий, то это объективно выражалось в «отключении» собственного времени развития большого числа малых народов-этносов и даже наций, которые входили в состав СССР. Узбеки, казахи и др. были переведены в режим «форсированного развития», что означало их собственную ускоренную индустриализацию и вхождение в систему союзного разделения и связи отраслей производства. Их собственное культурное развитие было выведено на второй план. Таким образом, происходил разрыв между производством и культурой, а значит - нарушение целостности социальной формы. И хотя в 1972 г. - к 50-летию образования СССР - официально была провозглашена «новая социально-историческая общность - советский народ», чудовищ- ные национальные конфликты, которые произошли накануне распада СССР, показывали, что реально такая новая общность не создана. Теперь ясно, что решить этот вопрос на основе создания общего для страны хозяйства и общей идеологии, а также социалистической культуры, без учета и глубинной проработки действия той социальной формы, которая существовала в СССР - союзу многочисленных больших и малых народов и определению условий субъектного статуса этой формы - фактически было нельзя.

Тем не менее некоторые уроки из этого недавнего прошлого для нашего современного общества можно все-таки извлечь. Что это за уроки?

Во-первых, для формирования общей методологической основы общественных наук они должны быть тесно связаны с государственно-общественной идеологией, коллективными интересами общества, входить в самосознание, ценности и цели самого производства. Это позволяет скорректировать инновационную направленность бытия современной России.

В чем состоит такая корректировка? Прежде всего в отказе от чисто техногенного подхода к развитию социальных институтов в нашей стране. Начиная с системы образования и заканчивая экономикой, все изменения здесь не могут быть основаны только или преимущественно на новых технологиях, на инструментально-информационном подходе, который с неизбежностью приводит к овеществлению всех сторон жизни общества, а вместе с этим - к мифологизации (фальсификации) социальных процессов и отношений. Общество, в котором процессы и содержание приобретают облик различных материализованных систем, которые поддаются точному количественному определению, неизбежно утрачивает свою собственную сущность и деградирует вместе с личностью. Следовательно, процесс инновационных изменений должен быть основан - как и науки, в которых он четко формулируется для разных сфер общественной жизни, на целостности социальной формы, в которую входит бытие этносов и его воздействие на социальное (включая информационно-коммуникационное пространство). Лишь на этой основе инновации не бу- 
дут разрушать общество и самобытность России.

Во-вторых, должна быть восстановлена целостность социальной формы. В условиях современной России это означает установление не только социально-этнических взаимодействий, но и формирование надэтнической символики, которая бы представляла собой «образ» всеобщего социального субъекта.

В-третьих, важное значение имеет идеологическое самоопределение страны - государственное и общественное. В идеологии (которая в данном случае не сводится к политическим интересам и власти) как раз будет выражено согласование между социальным и этническим: бытийная основа такого согласования сможет приобрести идейно-смысловое, ценностное выражение.

Таким образом, общественные науки в российском социуме, сохраняя свои общие понятия, методы анализа и др., получают такой общий и фундаментальный «срез» социума (общества в целом), который восстанавливает их объективность с позиций самобытности бытия России. Но поскольку в этой форме современное российское общество приобретает свое самосознание, свое место и роль в международной жизни, российское обществознание получает возможность исследования и других современных и прошлых сообществ - не в контексте абстрактных экономических и других законов, а в проявлении последних через бытие и особенности нашего общества. Все это означает, что мировая история, мировые хозяйственные процессы, мировые информационные связи существуют в единстве дискретного и непрерывного или в единстве и взаимодействии общего и особенного.

Идея культурно-исторических типов, которая возникла еще в XIX в. и показала самостоятельное сосуществование культурных миров, применительно к современной России частично сохраняет свою истинность, но вместе с тем - в контексте информационной планетарной целостности открывает более глубинный уровень единства человечества, который - как процесс глобализации - еще не завершил свое мировоззренческое и методологическое осмысление и обоснование, важное для фор- мирования общепланетарного обществоведения. Однако можно предполагать, что здесь также существует механизм воздействия общей социальной формы (субъекта), в пространстве которой также будет происходить процесс переработки и интеграции социальных и национально-этнических культурно-языковых и других пространств.

\section{СПИСОК ЛИТЕРАТУРЫ}

1. Арутюнов, С. А. Народы и культуры: развитие и взаимодействие / С. А. Арутюнов. - М. : Наука, 1989. - 247 с.

2. Бек, У. Общество риска. На пути к другому модерну / У. Бек. - М. : Прогресс-Традиция, 2000. $383 \mathrm{c}$.

3. Бергер, П. Социальное конструирование реальности / П. Бергер, Т. Лукман. - М. : Медиум, 1995. $-323 \mathrm{c}$.

4. Бодрийяр, Ж. В тени молчаливого большинства / Ж. Бодрийяр. - Екатеринбург : Изд-во УрГУ, 2000. - 95 с.

5. Бромлей, Ю. В. Очерки теории этноса / Ю. В. Бромлей. - М. : Либроком, 2009. - 440 с.

6. Бузский, М. П. Субъектная основа бытия и регулирования общества / М. П. Бузский. - Волгоград : Изд-во ВолГУ, 2002. - 247 с.

7. Бурдье, П. Структуры. Habitus. Практики / П. Бурдье // Современная социальная теория. Новосибирск : Изд-во Новосиб. гос. ун-та, 1995. C. 5-39.

8. Гидденс, Э. Устроение общества. Очерк теории структурации / Э. Гидденс. - М. : Академический проект, 2005. -528 с.

9. Гидденс, Э. Элементы теории структурации / Э. Гидденс // Современная социальная теория. - Новосибирск : Изд-во Новосиб. гос. ун-та, 1995. - C. 40-80.

10. Грачев, В. И. Социокультурная коммуникация как объект информационно-аксиологического анализа в современной художественной культуре / В. И. Грачев // Известия Российского государственного педагогического университета им. А.И. Герцена. - 2007. - Т. 8, № 41. - C. 69-75.

11. Кастельс, М. Информационная эпоха: экономика, общество и культура / М. Кастельс. - М. : ГУ ВШЭ, 2000. -608 c.

12. Моисеева, Н. А. Национальный характер как вектор бытия социума / Н. А. Моисеева. - М. : Изд-во РГАЗУ, 2012. - 300 с.

13. Социальная философия. Словарь / под общ. ред. В. Е. Кемерова, Т. Х. Каримова. - М. : Академический проект, 2003. -588 с. 


\section{REFERENCES}

1. Arutyunov S.A. Narody i kultury: razvitie $i$ vzaimodeystvie [Peoples and Cultures: Development and Interaction]. Moscow, Nauka Publ., 1989. 247 p.

2. Bek U. Obshchestvo riska: Na puti k drugomu modernu [Risk Society: On the Way to Other Modernist Style]. Moscow, Progress-Traditsiya Publ., 2000.383 p.

3. Berger P., Lukman T. Sotsialnoe konstruirovanie realnosti [Social Designing of Reality]. Moscow, Medium Publ., 1995. 323 p.

4. Baudrillard J. $V$ teni molchalivogo bolshinstva [In the Shadow of Tacit Most]. Ekaterinburg, Izd-vo UrGU, 2000. 95 p.

5. Bromley J.V. Ocherki teorii etnosa [The Sketches of the Theory of Ethnos]. Moscow, Librokom Publ., 2009. 440 p.

6. Buzskiy M.P. Subyektnaya osnova bytiya $i$ regulirovaniya obshchestva [Subjective Base of Life and Regulation of the Society]. Volgograd, Izd-vo VolGU, 2002.247p.

7. Bourdieu P. Struktury. Gabitus. Praktiki [Structures. Habitus. Practices]. Sovremennaya sotsialnaya teoriya [Modern Social Theory]. Novosibirsk, Izd-vo Novosib. un-ta, 1995, pp. 5-39.
8. Giddens E. Ustroenie obshchestva. Ocherk teorii strukturatsii [Society Organization. The Sketch of Structure Theory]. Moscow, Akademicheskiy Proekt Publ., 2005. 528 p.

9. Giddens E. Elementy teorii strukturatsii [Elements of Structure Theory]. Sovremennaya sotsialnaya teoriya [Modern Social Theory]. Novosibirsk, Izd-vo Novosib. un-ta, 1995, pp. 40-80.

10. Grachev V.I. Sotsiokulturnaya kommunikatsiya kak obyekt informatsionno-aksiologicheskogo analiza $\mathrm{v}$ sovremennoy khudozhestvennoy kulture [Sociocultural Communication as an Object of Information and Axiological Analysis in Modern Art Culture]. Izvestiya Rossiyskogo gosudarstvennogo pedagogicheskogo universiteta im. A.I. Gertsena, 2007, vol. 8, no. 41, pp. 69-75.

11. Kastels M. Informatsionnaya epokha: ekonomika, obshchestvo i kultura [Information Epoch: Economy, Society, Culture]. Moscow, GU VSHE Publ., 2000. 608 p.

12. Moiseeva N.A. Natsionalnyy kharakter kak vektor bytiya sotsiuma [National Character as a Vector of Society Life]. Moscow, Izd-vo RGAZU, 2012. 300 p.

13. Kemerov V.E., Karimov T.Kh., eds. Sotsialnaya filosofiya. Slovar [Social Philosophy. Dictionary]. Moscow, Akademicheskiy Proekt Publ., 2003. 588 p.

\section{Information About the Author}

Marat P. Buzskiy, Doctor of Philosophical Sciences, Professor, Department of Philosophy, Volgograd State University, Prosp. Universitetsky, 100, 400062 Volgograd, Russian Federation, Metamarat1@yandex.ru, socphil@volsu.ru.

\section{Информация об авторе}

Марат Павлович Бузский, доктор философских наук, профессор кафедры философии, Волгоградский государственный университет, просп. Университетский, 100, 400062 г. Волгоград, Российская Федерация, Metamarat1@yandex.ru, socphil@volsu.ru. 